\title{
Effect of controlling filamentous bulking sludge by Sequencing Batch Reactor Activated Sludge Process
}

\author{
Shengshu $\mathrm{AI}^{1}$, Linzhu DU ${ }^{1}$, Ziheng Wang ${ }^{1}$, Lubo Shao ${ }^{1}$, Hua Kang ${ }^{1}$, Fan Wang ${ }^{1}$, Dejun Bian ${ }^{1 *}$ \\ ${ }^{1}$ Key Laboratory of Urban Sewage Treatment of Jilin Province, Changchun Institute of Technology, Changchun, 130012, China
}

\begin{abstract}
Three groups of SBR reactors A, B and C with different aeration time were set up to culture the activated sludge which has already bulked. The results showed that the settling performance of activated sludge in reactor A changed a little, but reactors $\mathrm{B}$ and $\mathrm{C}$ had been significantly improved. High-throughput sequencing results showed that the aeration time had a significant inhibitory effect on the growth of Thothrix, and the longer the aeration time was, the more obvious the inhibition was. When the aeration time is more than $6 \mathrm{~h}$, the SBR mode can effectively inhibit filamentous sludge bulking, and the longer the aeration time, the better the effect.
\end{abstract}

\section{Introduction}

Activated sludge process is a common method in municipal wastewater treatment plant, which is widely praised in the world because of its high efficiency and low cost. Sludge bulking is a common problem in activated sludge process, which is mainly represented by loose sludge floc, poor settling performance of sludge, resulting in sludge loss in the system and deterioration of effluent quality. Due to the wide fluctuation range of water quality and large temperature difference in urban sewage treatment plants, it is easy to cause the growth of filamentous bacteria. And the excessive reproduction of filamentous bacteria is also one of the main causes of sludge bulking $[1,2]$. Studies have shown that when the composition of filamentous bacteria in the system reaches $1 \%-20 \%$, it may cause sludge bulking $[3,4]$.

The flocs of filamentous bacteria are long and loose. Compared with the functional bacteria, it mainly plays the role of skeleton in the bacterial micelles, and its longer flocs can extend out of the bacterial micelles. In this way, when the bacterial micelles absorb organic matter and oxygen filamentous bacteria will be the first to contact with them. Due to the physiological characteristics of filamentous bacteria, they can take the lead to meet their own needs and further occupy a dominant competitive position under the condition of low substrate concentration. Nowadays, there are four theories about filamentous expansion, which are kinetic theory [5], diffusion theory [6,7,8], energy storage theory $[9,10,11]$ and nitrogen oxide theory $[12,13,14]$. From the physiological characteristics of filamentous bacteria, they all explain the reason why filamentous bacteria are dominant in biological competition in the activated sludge process.

At present, the measures to solve the sludge bulking can be divided into specific technology and non-specific technology. Specific technology mainly depends on the change of external conditions to inhibit filamentous bacteria, such as adding oxidant [15], flocculant [16] and weight increasing agent, etc. Such technology can achieve good results in a short time, but it is difficult to fundamentally solve the problem of sludge bulking. Non-specific technology generally starts from the process itself, it changes the microbial growth environment, and uses natural competition to eliminate filamentous bacteria, such as adjusting load or adding biological selectors [17].

Many researchers have found that filamentous sludge bulking is more likely to occur in sewage treatment plants with continuous operation process, but rarely in sequencing batch process plants. It is generally believed that the sequencing batch process has a gradient of influent load, while the continuous process has been in low load operation. At the same time, the alternate aerobic-anaerobic environment of sequencing batch process is more conducive to inhibiting the growth of filamentous bacteria. At present, there are few studies on the inhibition of filamentous bulking by sequencing batch process. In this study, SBR process is used to cultivate activated sludge which has already bulked to improve its sedimentation performance and the mechanism is discussed, which provides a new way to solve the problem of sludge bulking.

\section{Materials and methods}

\subsection{Reactor and operation conditions}

The experimental SBR reactor is shown in Fig. 1, and its volume is about $3 \mathrm{~L}$. Three identical reactors are set up, namely $\mathrm{A}, \mathrm{B}$ and $\mathrm{C}$, which run for two cycles every day. 
The operation conditions are shown in Table 1, and the influent is instantaneous.

The reactor uses artificial water, starch as carbon source, $\mathrm{NH}_{4} \mathrm{Cl}$ as nitrogen source, $\mathrm{KH}_{2} \mathrm{PO}_{4}$ as phosphorus source, beef paste and peptone provide carbon, nitrogen, phosphorus and trace elements at the same time. The fluctuation range of influent COD is $249.8-391.3 \mathrm{mg} / \mathrm{L}, \mathrm{TN}$ is $27.93-39.63 \mathrm{mg} / \mathrm{L}$, TP is $1.61-$ $3.19 \mathrm{mg} / \mathrm{L}, \mathrm{NH}_{4}{ }^{+}-\mathrm{N}$ is $19.9-28.67 \mathrm{mg} / \mathrm{L}$.

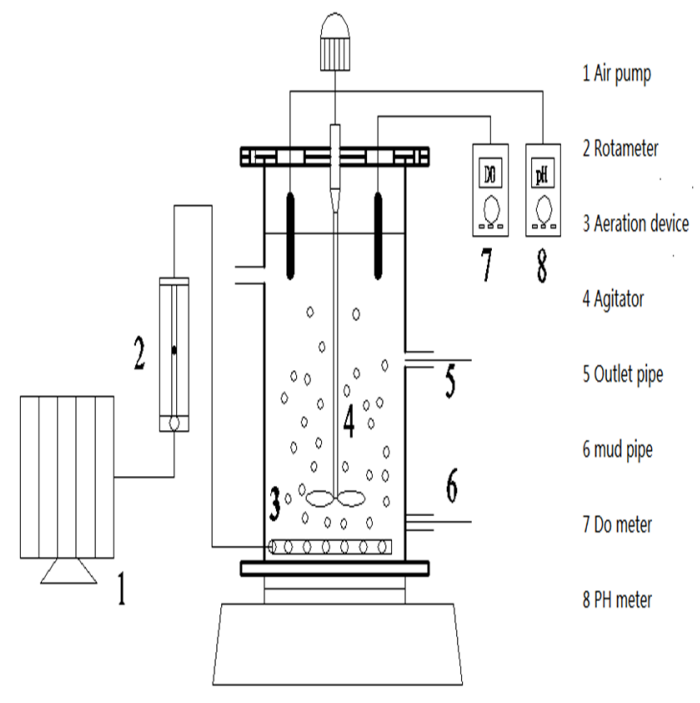

Fig 1. Diagram of the reactor

Table 1. Operation cycle table

\begin{tabular}{cccccc}
\hline \multirow{2}{*}{ group } & \multicolumn{5}{c}{ Operating conditions $(\mathrm{min})$} \\
\cline { 2 - 6 } & $\begin{array}{c}\text { Reac } \\
\mathrm{t}\end{array}$ & precipitate & discharge & leave & inflow \\
\hline A & 240 & 450 & 5 & 25 & 0 \\
B & 360 & 330 & 5 & 25 & 0 \\
C & 480 & 210 & 5 & 25 & 0 \\
\hline
\end{tabular}

\subsection{Detection method}

During the test, the water quality of the inlet and outlet water was tested every two days, and the sludge sedimentation performance index was tested every day. The COD, TN, $\mathrm{NH}_{4}^{+}-\mathrm{N}, \mathrm{TP}, \mathrm{SS}$ and MLSS were determined according to the standard method [18]. The calculation method of sludge sedimentation index (SVI) was shown in formula (1).

At the end of the operation stage, the Extracellular Polymeric Substances (EPS), intracellular glycogen, particle size and microbial community of each reactor were detected. EPS was extracted by improved heat extraction method, protein was measured by Folin phenol method, polysaccharide was measured by Anthrone sulfuric acid method, particle size was detected by Ambivalue eyetech particle size analyzer, and microbial community was detected by high-throughput sequencing technology.

$$
\mathrm{SVI}=\frac{S V_{30}}{M L S S}
$$

SVI is the sludge volume index, the unit is $\mathrm{mL} / \mathrm{g}$; $\mathrm{SV}_{30}$ is sludge settling ratio, the unit is $\mathrm{mL} / \mathrm{L}$; MLSS is the sludge, the unit is $\mathrm{g} / \mathrm{L}$.

\section{Results and discussion}

\subsection{Changes of Settling performance of sludge in different reactors}

Figure 2 shows the change of SVI in different reactors. It can be seen from the figure that SVI values of reactor A, $\mathrm{B}$ and $\mathrm{C}$ tended to decrease basically in the first 23 days, but the decrease range of reactor A was obviously the smallest. After 23 days, SVI of reactor B and C continued to decrease, while SVI of reactor A suddenly increased and last at the end. it is speculated that the filamentous bacteria in reactor A were inhibited in the initial stage because of the SBR operation mode. But due to the short aeration time, the available dissolved oxygen in the reactor was too little, which led to the filamentous bacteria being in the dominant position again in the natural competition and then grow a lot. At this time, the sludge in the reactor had turned grey. Under the influence of SBR mode, the sedimentation performance of reactors $B$ and $C$ gradually recovered, and the SVI value was stable below $100 \mathrm{~mL} / \mathrm{g}$ at the end of the experiment.

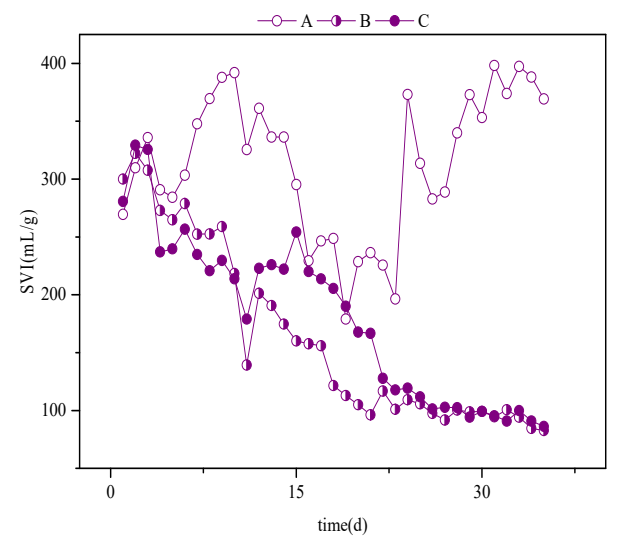

Fig.2. The changes of SVI in different reactors

\subsection{Sludge performance of different reactors}

Figure 3 shows the sludge performance of different reactors at the end of operation. Previous studies have shown that there is a certain correlation between EPS content and sedimentation performance in the process of sludge bulking. With the growth of filamentous bacteria, the content of protein (PN) gradually decreases, while the content of polysaccharide (PS) gradually increases $[19,20]$. Fig 3. (a) shows that the difference of PS in the three reactors is small, $\mathrm{PN}$ content $\mathrm{B}>\mathrm{C}>\mathrm{A}$, and the difference between $\mathrm{B}$ and $\mathrm{C}$ is small. Fig 3. (b) shows the intracellular glycogen content and sludge particle size in different reactors. Filamentous bacteria are a kind of organisms with strong carbon capture capacity but weak storage capacity. According to the difference of 
intracellular glycogen content, it can be seen that the glycogen content in reactor A is very small, while the glycogen content in reactor $B$ and $C$ is very high. It can be speculated that there are a lot of filamentous bacteria in reactor $\mathrm{a}$, but less in reactor $\mathrm{B}$ and $\mathrm{C}$.

Filamentous bacteria generally act as the skeleton of sludge in the sludge flocs, but if there are too many filamentous bacteria, the characteristics of sludge will be loose. The particle size of sludge can reflect the flocculation state of sludge to a certain extent, and the particle size in the figure is $\mathrm{D}_{50}$ data. It can be seen from the figure that the particle size of sludge is $\mathrm{C}>\mathrm{B}>\mathrm{A}$, and the particle size of sludge in reactor $\mathrm{C}$ is the largest. This phenomenon indicates that the flocculation state of sludge in reactor $\mathrm{C}$ is better, while the sludge in reactor $\mathrm{A}$ is the most loose. Combined with the analysis of sedimentation performance, a large number of filamentous bacteria may still remain in reactor $\mathrm{A}$.

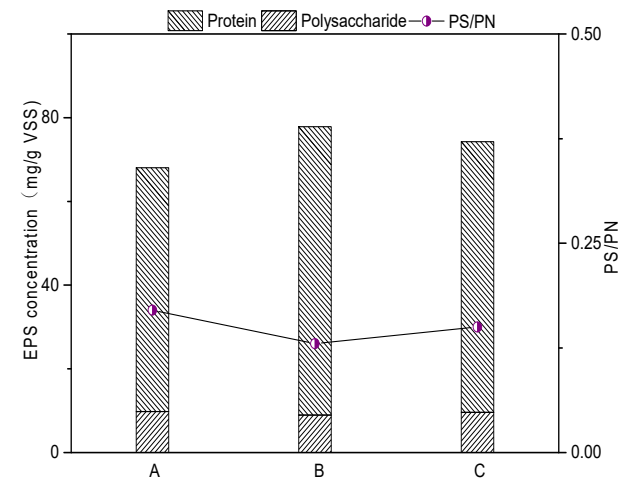

(a)

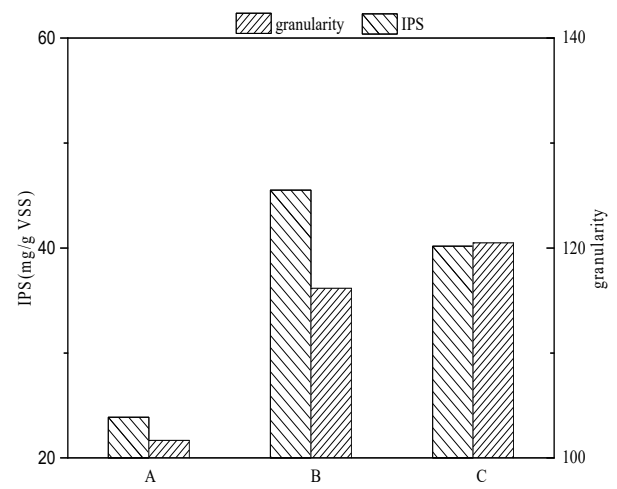

(b)

Fig 3. Sludge properties in different reactors

\subsection{Distribution of microbial community in different reactors}

Figure 4 shows the distribution of microbial community in the three reactors. Thiothrix and kouleothrix are both microfilaments, which can cause sludge bulking. It can be seen from the figure that Thiotrix accounts for $47.96 \%, 30.58 \%$ and $18.25 \%$ in reactors $\mathrm{A}, \mathrm{B}$ and $\mathrm{C}$ respectively, Kouletrix accounts for $0.07 \%, 2.0 \%$ and $2.8 \%$ in the three reactors. The most filamentous bacteria were found in reactor A, and the sludge bulking degree was relatively serious, which was the same as the previous study. The filamentous bacteria $\mathrm{B}$ and $\mathrm{C}$ in the reactor decreased gradually, and they were proportional to the aeration time.

The operation mode of SBR is not conducive to the growth of filamentous bacteria because the organic load in the reactor is large at the initial stage of react, and the organic matter available for microbial assimilation and growth is sufficient. According to the kinetic hypothesis [21], dissolved oxygen and organic matter are abundant in the initial stage of the reaction. At this time, the specific proliferation rate of bacterial micelles was higher than that of filamentous bacteria, and the bacterial micelles were in a dominant position in the natural competition. Secondly, with the continuous degradation of organic matter in the reaction process, the organic matter in the system is little at the end of the reaction. However, the mycelial micelles can still consume the nutrients stored in the body, and the filamentous bacteria have a weak ability to store energy. Due to the lack of nutrients, their growth will also be inhibited. The experimental data show that SBR operation mode can indeed inhibit filamentous sludge bulking. The effect is obvious when the aeration time is more than $6 \mathrm{~h}$, and the sludge settling performance is rapidly improved.

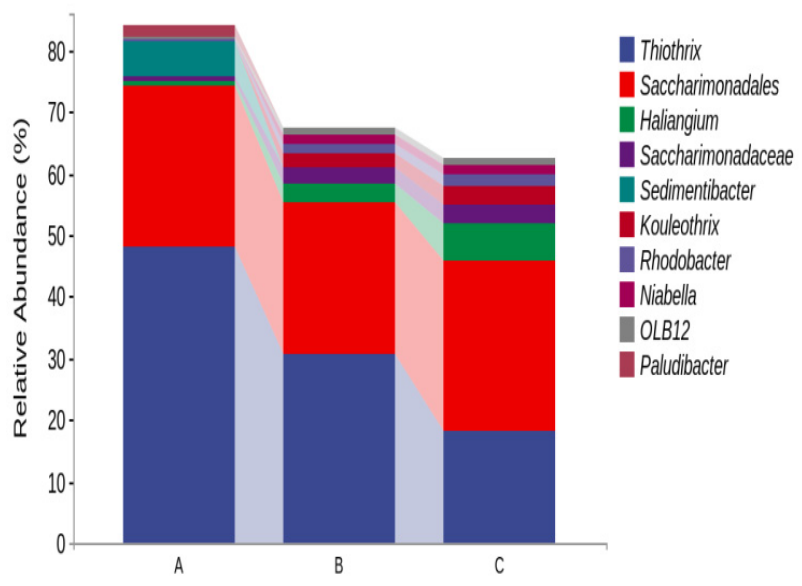

Fig 4. Distribution of microbial community in different reactors

\section{Conclusion}

Sludge bulking is a common problem in municipal wastewater treatment plants, which is often accompanied by the deterioration of effluent quality and sludge settling performance, resulting in the paralysis of water plants. Since the last century, many researchers have been working to develop a rapid and effective method to inhibit sludge bulking. However, due to the characteristics of filamentous bacteria, it is difficult to achieve this goal. This experiment starts with the process 
itself, and successfully recovers the performance of bulked sludge without the help of additional agents, and discusses its mechanism. The experimental data show that SBR operation is a new method with great potential to inhibit sludge bulking effectively.

In this study, sequencing batch process was used to culture activated sludge which had already bulked, and three groups of reactors with different aeration time were set up for comparison to explore the mechanism of inhibiting sludge bulking in SBR operation mode. The results are as follows:

1. SBR can improve the sludge settling performance, and the effect of it is obvious when the aeration time is more than $6 \mathrm{~h}$. When the aeration time is $4 \mathrm{~h}$, the sludge settling performance changes little due to the short aeration time.

2. SBR can inhibit the growth of filamentous bacteria, and the longer the aeration time is, the more obvious the inhibition effect is.

\section{Acknowledgement}

National Natural Science Foundation of china (51878067), Science and technology development program of Jilin Province (201903091SF), Scientific research program of Jilin Provincial Department of Education (JJKH20210684KJ).

\section{References}

1. Eikelboom Dick H. Process Control of Activated Sludge Plants by Microscopic Investigation. IWA Publishing: 2000-06-30.

2. O Krhutková, I Ruz icková, J Wanner. Microbial evaluation of activated sludge and filamentous population at eight Czech nutrient removal activated sludge plants during year 2000. Water science and technology: a journal of the International Association on Water Pollution Research, 2002,46.

3. J C Palm. Relationship between Organic Loading, Dissolved Oxygen Concentration and Sludge Settleability in the Completely-Mixed Activated Sludge Process. Journal (Water Pollution Control Federation). 1980, 52(10)

4. J Kappeler, W Gujer. Verification and applications of a mathematical model for "aerobic bulking". Water Res 1994, 28(2).

5. Chudoba J, Grau P, Ottova V. Control of activated sludge filamentous bulking - II. Selection of micro- organisms by means of a selector. Water Res 1973, 7(10).

6. O A Lau, P F Strom, D Jenkins. Growth kinetics of Sphaerotilus natans and a floc former in pure andcontinuous culture. Water Pollut Control Fed 1984, 56.

7. J Kappeler, W Gujer. Development of a mathematical model for "'aerobic bulking". Water Res 1994, 28(2)

8. M Sezgin, D Jenkins, DS Parker. A unified theory offilamentous activated sludge bulking. Water Pollut Control Fed . 1978, 50(2).
9. E Van den Eynde, L Vriens, M De Cuyper, H Verachtert. Plug flow simulating and completely mixed reactors with a premixing tank, in the control of filamentous bulking. Appl Microb Biotechnol, 1984, 19.

10. S C Chiesa, R L Irvine, J F Manning. Feast/famine growth environments and activated sludge population selection. Biotechnol Bioeng, 1985, 27.

11. S C Chiesa, R L Irvine. Growth and control of filamentous microbes in activated sludge: an integrated hypothesis. Water Res 1985, 19(4).

12. T G Casey, M C Wentzel, R E Loewenthal, GA Ekama, GvR Marais. A hypothesis for the cause of low F/M filament bulking in nutrient removal activated sludgesystems. Water Res 1992, 26(6).

13. $\mathrm{T}$ G Casey, M C Wentzel, G A Ekama, R E Loewenthal, GvR Marais. An hypothesis for the causes and control of anoxic-aerobic (AA) filament bulking in nutrient removal activated sludge systems. Water Sci Technol .1994, 29(7).

14. T G Casey, M C Wentzel, G A Ekama. Filamentous organism bulking in nutrient removal activated sludge systems. Paper 11: a biochemical/microbiological model for proliferation of anoxic-aerobic (AA) filamentous organisms. Water SA 1999, 25(4).

15. B Xie, X-C Dai, Y-T Xu. Cause and pre-alarm control of bulking and foaming by Microthrix parvicella: A case study in triple oxidation ditch at a wastewater treatment plant. Journal of Hazardous Materials, 2007, 143(1): 184-191.

16. S Paris, G Lind; H Lemmer; P A Wilderer. Dosing Aluminum Chloride To Control Microthrix parvicella. Acat hydrochimica et hudrobiologica. 2005, 33(NO.3).

17. R Pujol, J P Canler. Contact Zone: French Practice with Low F/M Bulking Control. Water Science and Technology, 1994, 29(7).

18. APHA (2007) Standard methods for the examination of water and wastewater 22nd ed. Washington D.C: American Public Health Association, American Water Works Association, and Water Environment Federation.

19. Q He, J Zhang, S X Gao, L Chen, W L Lyu, W Zhang, J Y Song, X L Hu, Rongfan Chen, Hongyu Wang, Jian Yu. A comprehensive comparison between non-bulking and bulking aerobic granular sludge in microbial communities. Bioresource Technology, 2019, 294.

20. W M Li, X W Liao, J S Guo, Y X Zhang, Y P Chen, F Fang, P Yan. New insights into filamentous sludge bulking: The potential role of extracellular polymeric substances in sludge bulking in the activated sludge process. Chemosphere, 2020, 248.

21. A Martins, K Pagilla, J Heijnen, M Loosdrecht. Filamentous bulking sludge critical - a review. Water Research. 2004, 38(4). 